Case Report

\title{
Acute Renal Failure after Consumption of Fish Gall Bladder
}

\author{
Nishant Raj Pandey, ${ }^{1}$ Bian Yu Yao, ${ }^{2}$ and Sudha Khakurel ${ }^{3}$ \\ ${ }^{1}$ Grande International Hospital, Kathmandu, Nepal \\ ${ }^{2}$ China National Petroleum Corporation Central Hospital, China \\ ${ }^{3}$ Tianjin Medical University General Hospital, Tianjin, China \\ Correspondence should be addressed to Nishant Raj Pandey; nishantrpandey@gmail.com
}

Received 29 October 2013; Accepted 12 December 2013; Published 2 February 2014

Academic Editors: L. Bojić and O. A. Sowande

Copyright (C) 2014 Nishant Raj Pandey et al. This is an open access article distributed under the Creative Commons Attribution License, which permits unrestricted use, distribution, and reproduction in any medium, provided the original work is properly cited.

A case of acute renal failure after consumption of fish gall bladder as traditional medical remedy is reported. The patient fully recovered with conservative treatment. The risk of acute kidney failure and even multiple organ dysfunction syndrome following ingestion of fish gall bladder is highlighted.

\section{Introduction}

In India, especially in Assam, people believe that fish gall bladder can improve vision and treat rheumatism. Chinese populations have a similar view and believe it improves eyesight and cure asthma [1]. Due to frequent consumption of fish gall bladder, fish bile poisoning cases care reported more commonly in China, India, Japan, and other Asian countries [2-4]. There were many reports about fish gall bladder poisoning leading to acute renal failure (ARF), acute liver injury, and therefore increasing mortality [5]. The incidence of ARF in fish bile poisoning is $55 \%-100 \%$, while the mortality rate accounts $91.7 \%$. Recently, studies have shown that fish gall bladder can also damage the heart, liver, and gastrointestinal tract and lead to multiple organ dysfunction syndrome (MODS) [1]. This is a case of gall bladder poisoning leading to acute renal failure in Chinese patient. This report is a whole new perspective on the pathogenesis of acute renal failure on complements about cases of poisoning in fish guts. This has a positive role in guiding treatment of fish bile poisoning, with obvious effect to improve its prognosis.

\section{Case Features}

A 56-years-old Chinese woman with past medical history of chronic bronchitis presented to a community hospital after consumption of grass carp fish gall bladder. Fish gall bladder was about $2 \times 2 \mathrm{~cm}$. Initial symptoms were nausea, vomiting, abdominal cramps, and watery diarrhea. After the onset of the symptoms she was treated in community level hospital with intravenous infusion for three days which did not improve her condition. After 5 days, she was presented in Tianjin Medical University General Hospital, Emergency Medical Center, for better management. On examination vital signs were stable. However, oliguria or anuria was observed in 24 hours and showed no edema.

Blood works revealed the following: WBC: $7.82 \times 10^{9} / \mathrm{L}$, $\mathrm{N}: 80.91 \%$, and HB: $168 \mathrm{~g} / \mathrm{L} ; \mathrm{ABG}$ revealed the following: $\mathrm{PH}$ : $7.50, \mathrm{PO}^{2}: 153 \mathrm{mmHg}$, Lac: $1.4 \mathrm{mmol} / \mathrm{L}, \mathrm{HCO}^{3-}: 25.7 \mathrm{mmol} / \mathrm{L}$, and BE: $2.7 \mathrm{mmol} / \mathrm{L}$. Urinanalysis reported: RBC: $0 / \mathrm{HPF}$, WBC: $0 / \mathrm{HPF}$, pathological casts: 0/LPF, specific gravity: $<1.005$, PH: 6.3; biochemistry reported the following: $\mathrm{Cr}$ : 277 umol/L, BUN: $13.31 \mathrm{mmol} / \mathrm{L}$, ALT: $95 \mathrm{U} / \mathrm{L}$, AST: $35 \mathrm{U} / \mathrm{L}$, and TBIL: $85.9 \mathrm{mmol} / \mathrm{L}$.

After admission intravenously reduced glutathione 1.2 grams was administrated once a day for live protection and injection of 9AA compound amino acid $250 \mathrm{~mL}$ was administrated once a day as supplement amino acids and intravenous pantoprazole $40 \mathrm{mg}$ was administrated twice a day. Oral sodium bicarbonate tablets $1 \mathrm{~g}$ were given thrice a day as it promotes fish bile toxins from the urethra, oral lactulose $10 \mathrm{~mL}$ was given thrice a day to promote fish bile toxins from the intestinal tract; and traditional Chinese medicine (Niaoduqing) was also given to protect renal function. After admission hemodialysis was performed three times. On second 
day of admission urine output increased to $1800 \mathrm{ml}$ and biochemistry reviewed Cr: 303 umol/L, BUN: $19.2 \mathrm{mmol} / \mathrm{L}, \mathrm{Na}$ : $127 \mathrm{mmol} / \mathrm{L}, \mathrm{CL}: 88 \mathrm{mmol} / \mathrm{L}$, and AG: 23.73. After the 11th day of admission, urine volume reaches $7600 \mathrm{~mL} / 24 \mathrm{~h}$, On arterial blood gas (ABG) Examination: $\mathrm{PH}: 7.41, \mathrm{PO}_{2}: 90 \mathrm{mmHg}$, Lac: $0.7 \mathrm{mmol} / \mathrm{L} ; \mathrm{HCO}^{3-}$ : $21.6 \mathrm{mmol} / \mathrm{L} ; \mathrm{BE}:-2.6 \mathrm{mmol} / \mathrm{L}$; On Urine examination: RBC: 7/HPF, WBC: $6 / \mathrm{HPF}$, pathological tube: 0/LPF, gravity: <1.005, PH: 6.3; On stool routine examination: occult blood negative.

Considering ARF adequate rehydration and electrolyte balance was maintained. While continuing the above drugs, $1000 \mathrm{~mL}$ of $5 \%$ Dextrose and sodium chloride injection and $0.9 \%$ sodium chloride injection $500 \mathrm{~mL}$ were given for adequate rehydration, and intravenous $10 \%$ potassium chloride $15 \mathrm{~mL}$ and oral salt capsules were administrated to maintain rehydration and electrolyte balance. However, patient still complained of recurrent vomiting and nausea. Therefore, fibrotic endoscopy was planned which showed chronic gastritis and duodenal inflammation, and systematic treatment was also given.

After a month of admission, urine volume was $2000 \mathrm{~mL} /$ $24 \mathrm{~h}, \mathrm{Cr}: 124 \mathrm{umol} / \mathrm{L}, \mathrm{BUN}$ : $7.1 \mathrm{mmol} / \mathrm{L}$; ALT: $45 \mathrm{U} / \mathrm{L}, \mathrm{AST}$ : 30 U/L, GGT45 U/L; Patients started normal diet. Her vomiting symptoms improvement and was then discharged.

\section{Discussions}

Most of the fish poising contains ciguatoxin [6] and mackerel poison, which are common in marine coral fish. Grass carp is usually without the toxin and does not have the characteristics of perishable mackerel [7]. However, grass carp bile contains highly virulent bile toxins, which cannot be damaged easily by ethanol or heat. One of the main toxic components is water soluble sodium cyprinol sulphate, which can lead to multiple organ dysfunctions [5]. Renal failure is the most commonly reported effects of fish bile poisoning [8]. It is believed that the fish bile results into serious damage to renal tubules. Deng et al. [9] found that light microscopy showed damages to epithelial cells in the proximal tubule and focal destruction of epithelial cells. Electron microscopy showed that mitochondria crista of epithelial cells in the proximal tubules had decreased or disappeared and the renal mesangium was extended. Glomerular cells were swollen and podocytes were partially fused; lysosomes were broken. Partial potocytic processes are fused. It is believed that the toxin in fish gall bladder damages or breaks lysosomes, meanwhile inhibiting cytochrome oxidase and blocking cellular energy metabolism, so as to cause necrosis of the proximal tubular epithelial cells. From our case, we can hypotise that due to frequent vomiting, diarrhea and insufficient intake there was significant decreased blood volume, leading to kidney blood stasis which worsen renal failure. Therefore, for these patients on dialysis, active rehydration should have significant role in prognosis.

Recently, studies have shown that fish gall bladder can also damage the heart, liver, and gastrointestinal tract and lead to multiple organ dysfunction syndrome (MODS) in addition to ARF [9]. The effect of fish bile in human body mechanism needs further study and physicians should have more attention in management of fish bile poising for better prognosis.

\section{Conflict of Interests}

The authors declare that they have no conflict of interests.

\section{Authors' Contribution}

Nishant Raj Pandey and Bian Yu Yao contributed equally to this work.

\section{References}

[1] X. L. Cheng, Z. I. Wang, and L. M. Reng, "Fish gall bladder poisoning damage liver, renal and heart," Chinese Journal of Integrative Medicine, vol. 3, pp. 238-239, 1991.

[2] D. S. W. Cahn, C. K. Yeung, and M. K. Chan, "Acute renal failure after eating raw fish gall bladder," British Medical Journal, vol. 290, no. 6472, article 897, 1985.

[3] Y. Yamamoto, O. Wakisaka, S. Fujimoto et al., "Acute renal failure caused by ingestion of the carp gall bladder-a report of 3 cases, with special reference to the reported cases in Japan," Nihon Naika Gakkai Zasshi, vol. 77, no. 8, pp. 1268-1273, 1988.

[4] R. N. Sahoo, M. K. Mohapatra, B. Sahoo, and G. C. Das, "Acute renal failure associated with freshwater fish toxin," Tropical and Geographical Medicine, vol. 47, no. 2, pp. 94-95, 1995.

[5] N. S. Singh, L. K. S. Singh, I. Khaidem et al., "Acute renal failure following consumption of raw fish gall-bladder from Manipur," Journal of Association of Physicians of India, vol. 52, pp. 743-745, 2004.

[6] C. R. Ou and H. Q. Tang, "Study on isolation of bacteria produce histamine degrading enzyme and characterization of histamine degrading enzyme in mackerel," Ningbo University, 2012.

[7] C. M. Perez, P. A. Vasquez, and C. F. Perret, "Treatment of ciguatera poisoning with gabapentin," The New England Journal of Medicine, vol. 344, no. 9, pp. 692-693, 2001.

[8] S. J. Goldstein, R. M. Raja, M. Kramer, W. Hirsch, and E. B. May, "Acute hepatitis and renal failure following ingestion of raw carp gallbladders-Maryland and Pennsylvania, 1991 and 1994," Journal of the American Medical Association, vol. 274, no. 8, article 604, 1995.

[9] Y. Deng, G. Xiao, Y. Jin et al., "Multiple organ dysfunction syndrome due to ingestion of fish gall bladder," Chinese Medical Journal, vol. 115, no. 7, pp. 1020-1022, 2002. 


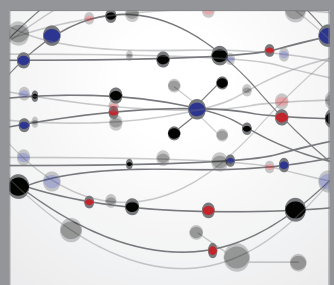

The Scientific World Journal
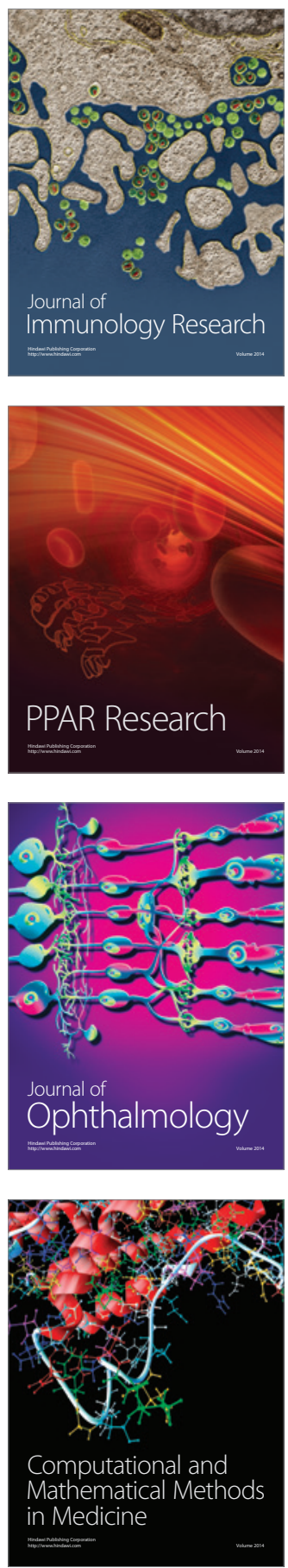

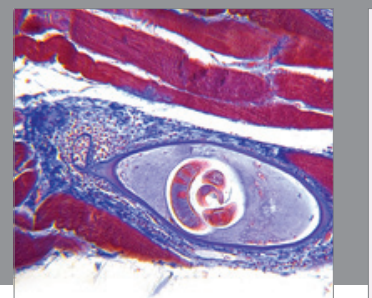

Gastroenterology

Research and Practice
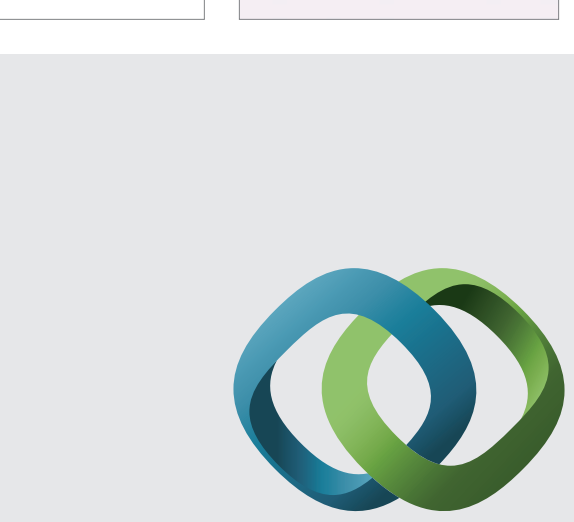

\section{Hindawi}

Submit your manuscripts at

http://www.hindawi.com
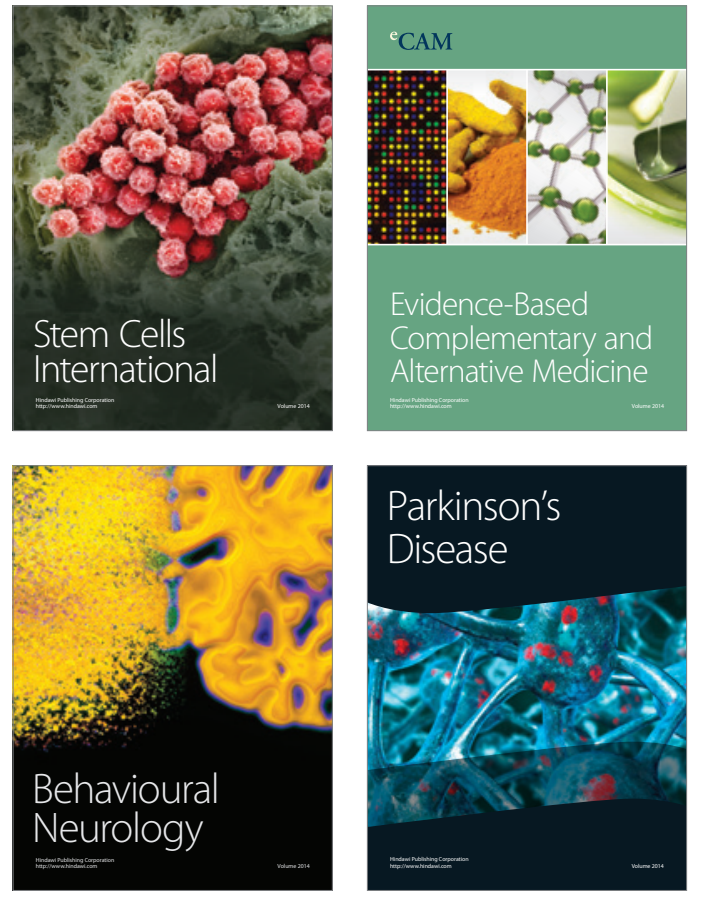
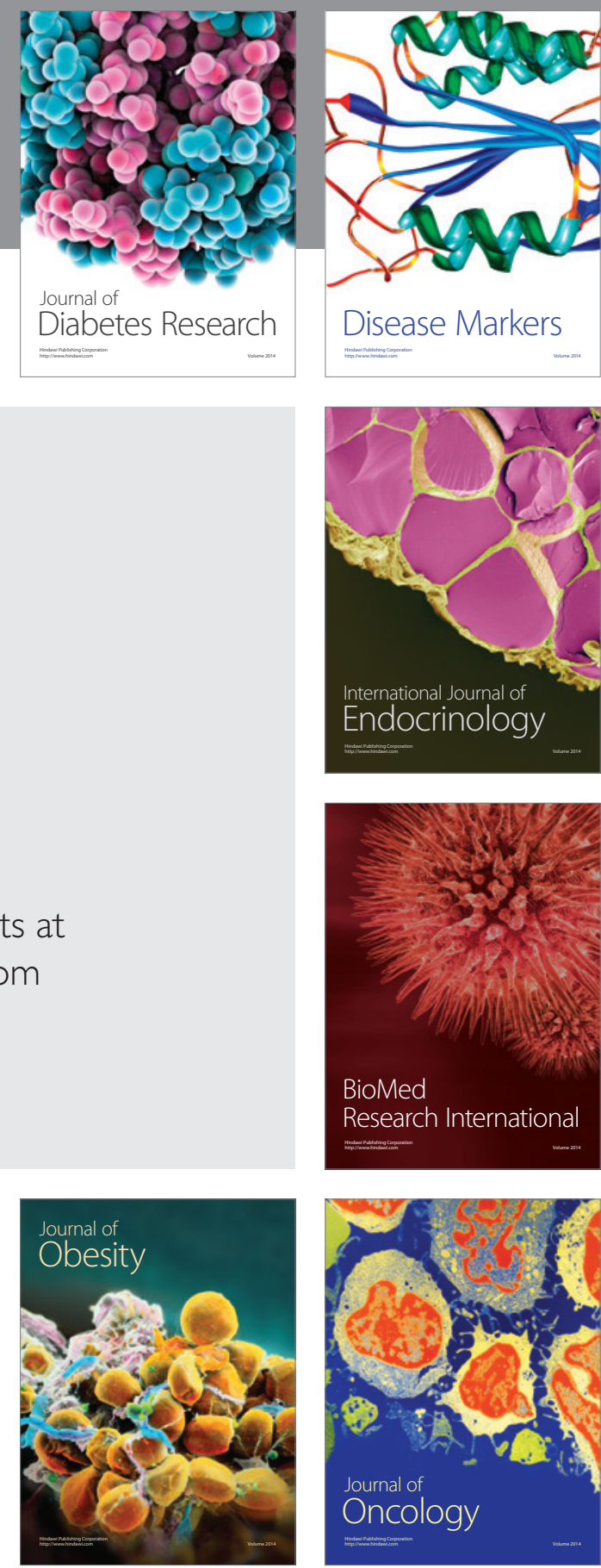

Disease Markers
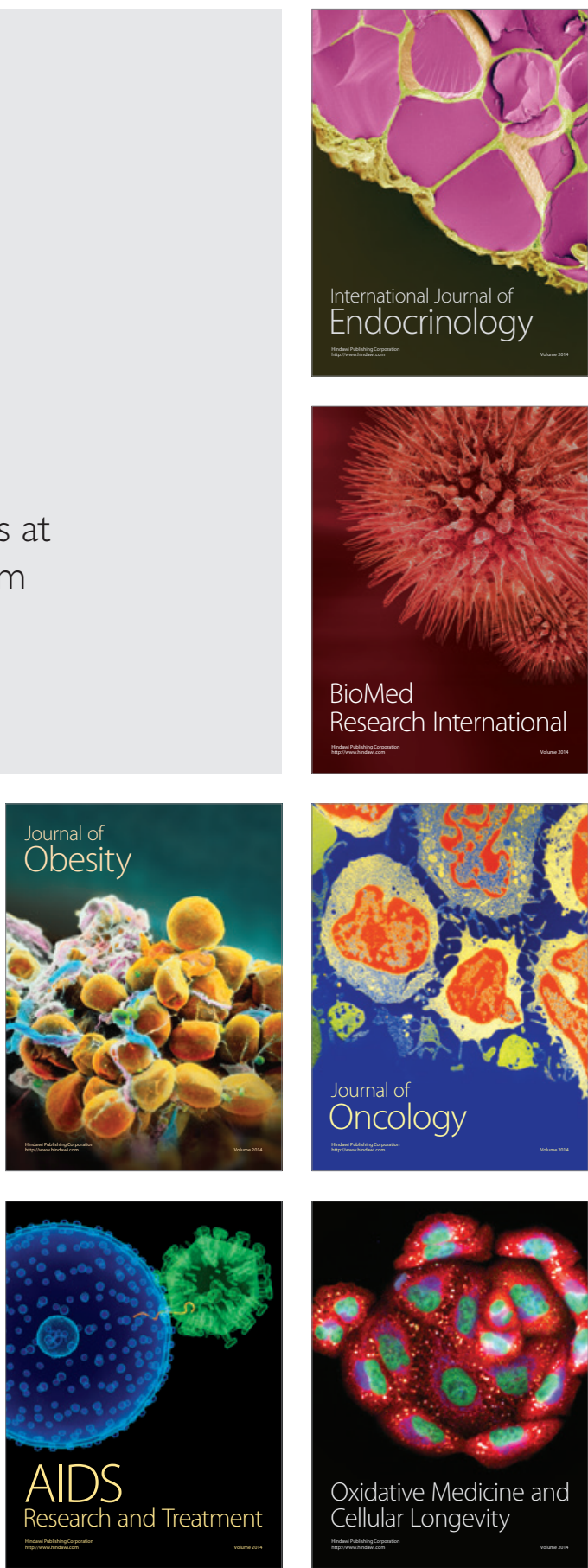